\title{
A SWOT analysis of planning support systems
}

\section{Guido Vonk}

Urban and Regional Research Centre, Utrecht and Copernicus Institute for Sustainable Development and Innovation, Utrecht University, PO Box 80.115, 3508 TC Utrecht, The Netherlands; e-mail: g.a.vonk@gmail.com

\section{Stan Geertman}

Urban and Regional Research Centre, Utrecht and International Institute for Geo-Information Science and Earth Observation, PO Box 6, 9500 AA Enschede, The Netherlands; e-mail: s.geertman@geo.uu.nl

\section{Paul Schot}

Copernicus Institute for Sustainable Development and Innovation, Utrecht University, PO Box 80.115, 3508 TC Utrecht, The Netherlands; e-mail: p.schot@geo.uu.nl Received 9 July 2005; in revised form 28 September 2005

\begin{abstract}
Insight into the strengths, weaknesses, opportunities, and threats (SWOT) of planning support systems (PSS) is fragmented between users and system developers. The lack of combined insights blocks development in the right direction and makes potential users hesitant to apply PSS in planning. This study presents SWOT of PSS from a combined user-developer perspective. We first express them in terms of combinations of planning task, PSS information function, and user, and subsequently use a literature survey, a series of interviews, and a web survey to gather views from developers, users, and PSS experts. The analysis shows that planners mainly use simple information storage and retrieval systems for exploration tasks, while the majority of PSS are technically much more advanced and aim to support complex tasks. The potential of these advanced PSS can only be realized if planners and system developers start to share knowledge and demands and identify opportunities in a cooperative PSS-development process. Without such a process, the advantages and opportunities of PSS will remain unexploited.
\end{abstract}

\section{Introduction}

Geo-information technologies are gradually becoming used to support spatial policy tasks (Stillwell et al, 1999b). Planning support systems (PSS) are a subset of these geoinformation technologies dedicated to aid those involved in planning to explore, represent, analyze, visualize, predict, prescribe, design, implement, monitor, and discuss issues associated with the need to plan (Batty, 1995). PSSs bring together the functionalities of geographical information systems (GIS), models, and visualization, to gather, structure, analyze, and communicate information in planning. They take the form of 'information frameworks', which integrate the full range of information technologies useful for supporting the specific planning context for which they are designed (Geertman and Stillwell, 2003b; Klosterman, 1997). Tools like GIS and spatial decision support systems (SDSS) are related to PSS and some overlap exists. In general, however, PSS aim to focus purely on planning support, while many SDSS and GIS technologies can be used for planning support if required, but are not solely dedicated to that use. We therefore exclude SDSS and GIS from our current research and focus on typical PSS [for more information on general differences between PSS, GIS, and SDSS, see Geertman and Stillwell (2003b)]. Many see PSS as capable of supporting spatial planning in terms of handling complexity, thereby increasing the quality of plans and decreasing time and money spent (Batty, 1995; Bishop, 1998; 
Brail and Klosterman, 2001; Couclelis, 2003; Geertman and Stillwell, 2003a; Laninga, 2001; Stillwell et al, 1999b).

Although the history of computer support in planning dates back to the 1950s (Harris, 1960), the practical realization of PSS has become technically possible only with the rise of powerful microcomputer technology in the last few decades. Inventories show that currently a large diversity of PSS exists and that 'UrbanSim', 'CommunityViz', and 'What If' are currently the best known PSS among experts (Brail and Klosterman, 2001; Geertman and Stillwell, 2003a; 2004; Vonk et al, 2005a). Nevertheless, most PSS are at a laboratory stage and PSS are hardly used in planning practice by the intended users (Geertman and Stillwell, 2004). This is mainly because there is little awareness of, and experience with, PSS among potential users (Vonk et al, 2005a). System developers, on the other hand, have little awareness of the demands of users (Geertman and Stillwell, 2004). Development of PSS towards a full-grown technology is expected to benefit from the combination of knowledge from both sides (Lundvall, 1988; Oudshoorn and Pinch, 2003). At present, aspects of a combined view only exist fragmentarily in the heads of a few experts, which hampers the development of appropriate PSS. This is problematic, considering the assumed potential of PSS to improve planning.

In this paper we generate insights into strengths, weaknesses, opportunities, and threats (SWOT) of PSS, combining the technical knowledge of system developers with the practical knowledge of users and views of PSS experts who have some knowledge of both sides, with the overall aim of enhancing PSS development and application. The underlying assumption is that such combined insights may make users more aware of PSS, convince them of their value, and subsequently stimulate application and willingness to cooperate with system developers to improve existing PSS. Likewise, such insights may give system developers a new stimulus to improve their instruments. Hence, such insights may become a basis on which users and system developers may be brought together for cooperative innovation in PSS. In this way, combined technical and practical insights may constitute an important contribution to the development and application of PSS technology.

\section{Theoretical framework}

\subsection{Task - technology - user fit}

Studies in the fields of innovation and management sciences show that an information and communication technology (ICT) cannot be fully evaluated on its SWOT without taking into account its suitability for performing the task at hand and for the user who would use it (Beaudry and Pinsonneault, 2005; Davis, 1989; Dishaw and Strong, 1999; Dishaw et al, 2002; Goodhue and Thompson, 1995; Rogers, 2003; Venkatesh et al, 2004). We regard PSS as a particular type of ICT and have developed a framework to study SWOT of PSS in terms of present-day and future fit between planning task, PSS (technology), and user (see figure 1). In this paper, 'strengths and weaknesses' refer to the present-day fit and opportunities and threats to the fit that can be expected in the future. For this purpose we specified the concepts of planning task, PSS, and user, by means of a classification.

fit?

fit?

Planning task
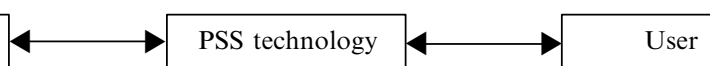

Figure 1. Conceptualization of the SWOT (strengths, weaknesses, opportunities, and threats) analysis in terms of fit between planning task, planning-support system (PSS) technology, and user. 


\subsection{Classification of planning tasks}

Planning processes are shaped in a multitude of ways. The dynamic character between and within planning processes makes it impossible to make a general theory of how to plan, let alone to make a suitable classification of programmatically applied planning tasks (Alexander, 1998; Archibugi, 2004; Mandelbaum, 1979). Nonetheless, some basic tasks or activities occur repetitively in various planning styles and systems, since they are directly related to the core of planning as a means of 'reasoned' exploring and anticipating the future or solving existing problems in society, alone or with others (Geertman and Stillwell, 2003b). We distinguish the following seven planning stages:

(1) problem definition, with the tasks being problem signalling and agenda setting, etc;

(2) problem exploration and analysis, with the tasks being inventory of conditions and analysis of trends;

(3) change exploration and analysis, with the tasks being development of alternatives/ scenarios, impact-assessment research, evaluation of alternatives, development of plan, etc;

(4) consultation, with the tasks being discussion and negotiation of goals, alternatives, implementation modes, etc;

(5) decision, with the tasks being decision making on goals, alternatives, implementation modes, etc;

(6) implementation, with the tasks being dissemination and starting actions, etc;

(7) monitor and evaluate effects.

Depending on the planning style, the stages occur in various combinations of sequences.

Figure 2 shows these stages and tasks in relation to the classified PSS.

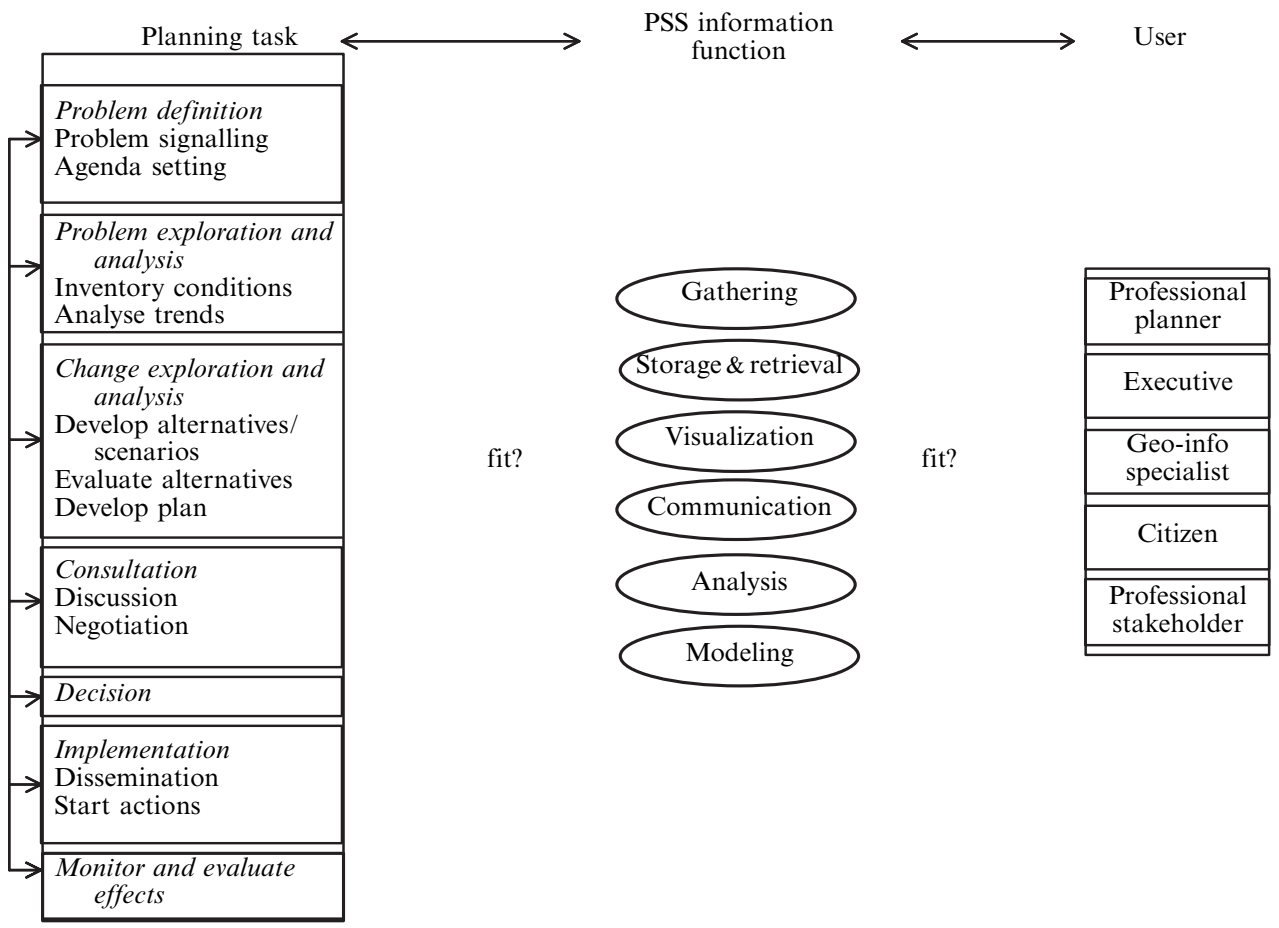

Figure 2. Conceptual framework describing the fit of combination of planning task-planning support system (PSS) information function - user. 


\subsection{Classification of PSS}

Instruments for planning support have previously been classified based on type of technology and planning type or application field (Brail and Klosterman, 2001; Geertman and Stillwell, 2003a). For this study, a more task-dedicated classification was used, based on the function of a system with respect to handling information in planning processes (Burrough and McDonnel, 1998). We distinguish six information-handling functions:

(1) information gathering, for example, traffic-monitoring systems;

(2) information storage and retrieval, for example, geo-databases;

(3) information visualization, for example 3D visualization kits;

(4) information communication, for collaboration between actors, for example, cognitive mapping systems, electronic brainstorming systems, electronic collaborative sketching systems;

(5) information analysis, to generate new information from existing information, for example, multicriteria-analysis systems, statistical trend analysis systems;

(6) system modeling, to simulate processes based on information in the system, for example, land-use models, physical process forecasting models.

Figure 2 shows the subdivision of PSS into these six classes.

\subsection{Classification of users}

The history of planning shows periods in which planning was mainly the domain of executives, planners, and geo-information specialists, and also more participatory periods in which there was increased involvement of stakeholders and citizens in planning (Brail and Klosterman, 2001; Geertman, 1996; Hall, 2002). Mainly since the 1990s, participation in planning has increased and is expected to increase further in the near future (Brail and Klosterman, 2001; Driessen et al, 2001; Margerum, 2002; Stillwell et al, 1999a). Based on this trend, we distinguish the following planning actors as main users of PSS in present-day and future planning practice:

(1) professional planners, including designers, planning policy workers, and planning consultants;

(2) executives, including managers and politicians;

(3) geo-information specialists working within planning organizations, consultancy organizations, or universities;

(4) citizens;

(5) professional stakeholders, including representatives of groups of people or organizations. Actors not among these five are not considered main users of PSS in planning practice. The identified users are shown in figure 2.

\subsection{Conceptual model of task - technology - user fit for PSS}

The conceptual model in figure 2 reflects the possible linkages between planning tasks, information (handling) functions of PSS, and users. In the following sections we show how this framework was applied to investigate SWOT of PSS.

\section{Method}

To measure present and future task-technology-user fit, we combined the technical expertise on this subject of system developers with the more practice-oriented expertise of users. We enriched this knowledge base with the views of PSS experts, since they are expected to have knowledge both of the developers' and of the users' sides. We realize that these three groups are not fully distinct in their knowledge and experience, and account for this in our analysis. The knowledge and expertise of the three groups was gathered between June and December 2003. 
System-developer views of PSS have been quite well recorded in the scientific literature. Therefore, we tracked their perspectives on task-technology-user fit by conducting a literature survey. For the literature survey, fifty-eight PSS were entered in a large table and compared on the basis of a wide range of criteria, related to planning task, PSS information function, and user. In the selection of systems we applied a broad definition of PSS, including all instruments that claim to be a PSS. This allows us to account for the discourse among experts on the content of the PSS concept concerning exactly what entails dedication to planning tasks and planning actors. Furthermore, we limited ourselves to literature published after 1998 to account for the shifting meaning of PSS with advancing technological possibilities. We included books and reports on PSS, papers from geographic information science related conferences, and journals. The two main sources were the two books on PSS edited by Brail and Klosterman (2001) and Geertman and Stillwell (2003a).

User views of PSS were gathered by holding a series of interviews among fortythree employees of twelve highly comparable Dutch regional planning organizations. In particular, we interviewed three of the archetypes of users identified above who currently have an important role in using and evaluating PSS: the geo-information specialist, the planner, and the executive. Since we focus on the fit of the PSS with a set of planning tasks and users that are common to virtually all planning organizations in Western and non-Western societies, independent of the planning system, planning style, legal system, etc, specific to each country, we expected these archetypes to be capable of providing us with a good representative overview of users perspectives on PSS technology.

In addition, earlier studies show that the state of the technology itself is highly comparable in Western societies (Brail and Klosterman, 2001; Geertman and Stillwell, 2004; Klosterman and Pettit, 2005; Vonk et al, 2005a).

In the end, most of the participants were geo-information specialists (15), professional planners (12), and executives (3), but people with strongly related specializations also took part (13). The interviews were carried out in groups, during twelve sessions of several hours each.

Expert views on PSS were gathered by means of conducting a worldwide web survey. Via several PSS-related listserv e-mail networks, 800 persons interested in PSS were asked to participate. Among the total of forty respondents, the thirty persons who indicated that they had had practical experience with at least two PSS were considered experts. The survey consisted of open questions on SWOT of PSS, as well as closed questions in order to express the perceived fit of a range of combinations of planning tasks, PSS, and user, and to identify experience with these combinations. Respondents could judge the fit by selecting from 'not useful', 'neutral', '(very) useful', and 'don't know'.

During interpretation, the findings from the literature survey, the interviews, and the web survey were combined and interpreted in terms of the conceptual framework shown in figure 2. Subsequently, the findings were developed into an aggregate overview of SWOT of PSS.

\section{Results}

\subsection{System-developer views}

Inspection and analysis of literature-survey data produced the results described below. Table 1 shows the number of PSS from our sample of fifty eight which are dedicated to the information functions, planning tasks, and user types identified in the conceptual framework. Note that a single PSS can be dedicated to multiple tasks, information 
Table 1. Number of planning-support systems (PSS) dedicated to a range of planning tasks, information functions, and user types.

Planning task

PSS information

Users

function

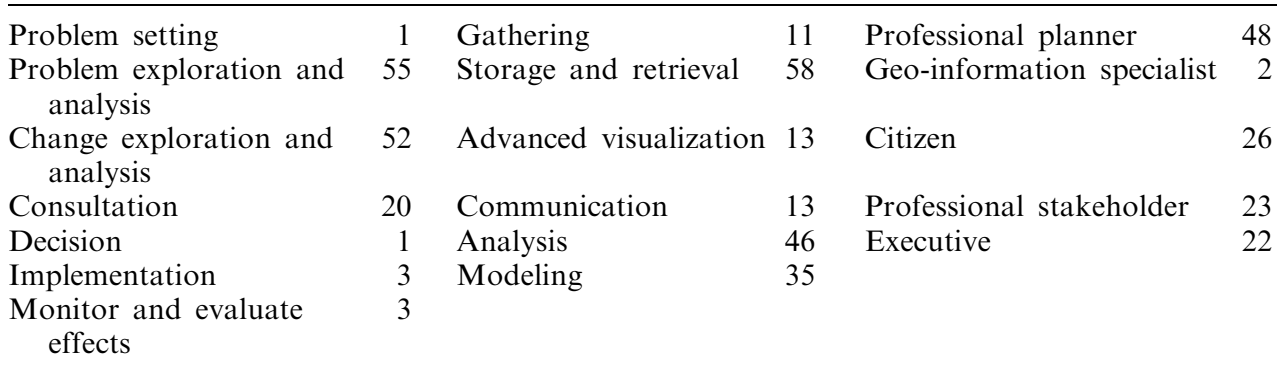

functions, and users: for example, most PSS with an analysis function also do storage and retrieval of data.

Regarding planning tasks, the literature survey suggested that very few systems are dedicated to support problem definition and decision making. A few systems support implementation in terms of dissemination, and a few other systems support monitoring. Somewhat more systems focus on consultation of stakeholders and citizens. In recent years, significant progress has been made in citizen-oriented and web-based systems for consultation in web-based settings, and the number of PSS for consultation in collaborative settings has also expanded (Craig et al, 2002, page 383; Jankowski and Nyerges, 2001, page 273). However, the majority of current systems focus on support of problem and change exploration and analysis.

Regarding PSS information functions, the literature suggested that a minority of systems focus on gathering information, advanced visualization, and communication of information. By far the majority of systems focus on analysis and modeling. Although many PSS with storage and retrieval functionality were found, only very few are actually dedicated to this use. Most systems incorporate it as a necessary condition for analysis and modeling, which is the emphasis in these systems.

Regarding PSS users, the literature survey found almost no systems dedicated to executives. Many more system focus on supporting participatory forms of planning with stakeholders or citizens. However, most systems focus on supporting planners themselves in doing their planning tasks. Among these systems are many PSS that incorporate or consist totally of land-use models. Only a part of these systems is actually user-friendly enough to be used by professional planners: those that are not seem to be suitable for use by geo-information specialists. Apart from their being difficult to use, many systems remain one-off applications - operated by the university researcher who developed the PSS in the first place.

\subsection{User views}

The results obtained from the interviews are described below. Table 2 provides a summary of these results, in terms of interviewee perceptions of usefulness of PSS dedicated to a range of planning tasks, information functions, and users. Most users claimed that they currently make very limited use of PSS in their daily practice, so that most of their judgments indicate estimated present-day and future usefulness.

Regarding planning tasks, the interviews suggested that users see little use for PSS in problem definition. For tasks in the problem exploration and analysis stage, however, the interviewees regard the use of PSS as particularly useful. They indicated that 
Table 2. Usefulness of planning-support systems (PSS) dedicated to a range of planning tasks, information functions, and users as indicated by PSS users.

Planning task

PSS information

User

function

\begin{tabular}{|c|c|c|c|c|c|}
\hline Problem definition & - & Gathering & + & Professional planner & + \\
\hline $\begin{array}{l}\text { Problem exploration and } \\
\text { analysis }\end{array}$ & ++ & Storage and retrieval & ++ & $\begin{array}{l}\text { Geo-information } \\
\text { specialist }\end{array}$ & ++ \\
\hline $\begin{array}{l}\text { Change exploration and } \\
\text { analysis }\end{array}$ & 0 & Visualization & ++ & Citizen & + \\
\hline Consultation & + & Communication & + & Professional stakeholder & + \\
\hline Decision & - & Analysis & + & Executive & - \\
\hline Implementation & + & Modeling & 0 & & \\
\hline $\begin{array}{l}\text { Monitor and evaluate } \\
\text { effects }\end{array}$ & + & Combinations & ++ & & \\
\hline
\end{tabular}

most professional planners nowadays use computer-based systems for early and rather simple exploratory tasks, such as making inventories of conditions and, sometimes, analyzing spatial interactions and trends, which can be the basis of scenario formation. In the stage of change exploration and analysis, PSS are currently rarely used. Nonetheless, some of the users interviewed think that application of PSS for future-oriented tasks in this stage could be very useful. In the consultation stage of current planning, PSS are hardly made use of, but users see increasing opportunities due to the intensified consultation of professional stakeholders and citizens. In the decision stage, PSS are hardly used at all. Users almost unanimously indicated that the nature of decision making allows little space for computer-based instruments.

In the implementation stage, professional planners disseminate the plan by publishing their products on the Internet for citizen and professional planners. For monitoring and evaluating effects, the systems used range from simple systems with periodically updated maps to more advanced real-time traffic-monitoring systems. These systems are seen as useful.

Regarding the PSS information function, the interviews suggested that many professional planners nowadays use dedicated systems which combine information storage and retrieval with simple analysis and visualization. These technologically simple systems are the systems with which planners have had most experience, and usually these are also the only systems they use. In particular, younger planners are often eager to use these systems. Most professional planners have access to such applications, which are usually intranet-based desktop viewing systems which retrieve information from a central geo-database. Geo-information specialists in two organizations indicate that, in response to this demand, they were developing more systems dedicated to support these tasks. Some users also see promise in more technically advanced systems or toolboxes that combine all information functions and that are able to support all exploration and analysis activities on their desktop. One thing they find particularly useful is the ability of such PSS to help find spatial relations and patterns that lead to a determination of the physical suitability of areas. This is information that can be used to delimit possible future development areas. As an example, users indicated that professional planners could benefit from a viewer with metadata, trend-analysis tools, spatial scenario models, and visualization tools for these purposes. Although such more advanced systems are seen as promising, according to most users they need further development. Currently, many of these systems are not regarded as fit for present-day planning and are seen as far too complex to be handled by professional planners. In their current state, users view the models mainly as tools for geo-information specialists, 
and as being mostly used in the academic world. For communication, we distinguish web-based consultation systems and collaborative systems that support consultation in meetings. The web-based systems are now mostly used for dissemination of planning results, but two-way communication could become very useful in enabling real consultation. Such systems are seen as useful since they will provide lots of different views on which to base designs. The meeting-support systems are now used in their simplest forms - a smart board - by two organizations. Users see such systems as particularly useful if many information functions are integrated.

Regarding the PSS users, the interviews suggested that professional planners nowadays leave most analysis tasks to geo-information specialists. Most planners themselves only use viewer-type PSS. The users also see PSS as useful for citizens and professional stakeholders if participation increases. Many organizations are already experimenting with intensified consultation in their planning processes. A new range of systems that support this could be useful in such processes, enabling citizens and stakeholders to carry out their own exploration and analysis tasks, while such systems would give them better informed views in the consultation process. The majority of users agree that PSS are scarcely useful for executives. Only the most basic tools, which provide easily interpretable, crystal-clear images at high speed could be used to support the executive in the political process. Decision makers need to be able to make good choices quickly about highly complex issues, a process which PSS are thought to obstruct.

Furthermore, the exactness of the outcome of analytical systems is also seen as different from reality - where uncertainty and ambiguity rule. Nonetheless, some users see some room for PSS as they do not accept the obscure character of many decisionmaking processes and indicated that such a system could help to present information clearly, thereby increasing the transparency of the 'black box' of policy making. Users in one organization have even had positive experiences with highly advanced systems used by politicians to support their decisions.

\subsection{Expert views}

Inspection and analysis of web-survey data revealed the following results. Figure 3 shows the results of an analysis performed in order to find dependence patterns in the variables concerning experience and usefulness. The two graphs in figure 3 suggest that the more experience one has, the more one will judge PSS as useful. Although these judgments come from experts only, this result is a strong argument for enhanced application of PSS. Figure 4 shows expert respondents' judgments of the level of usefulness of PSS for a range of information functions, users, and planning tasks.
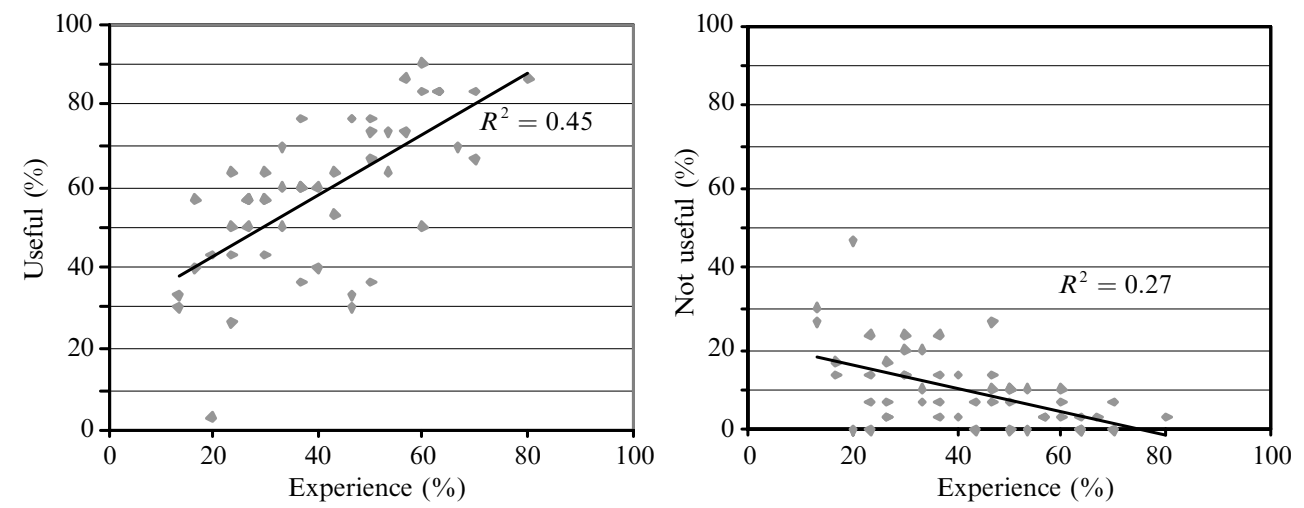

Figure 3. Relations between experience and usefulness of planning-support systems (PSS) average frequency of thirty users on fifty aspects of PSS in relation to planning task and user. 


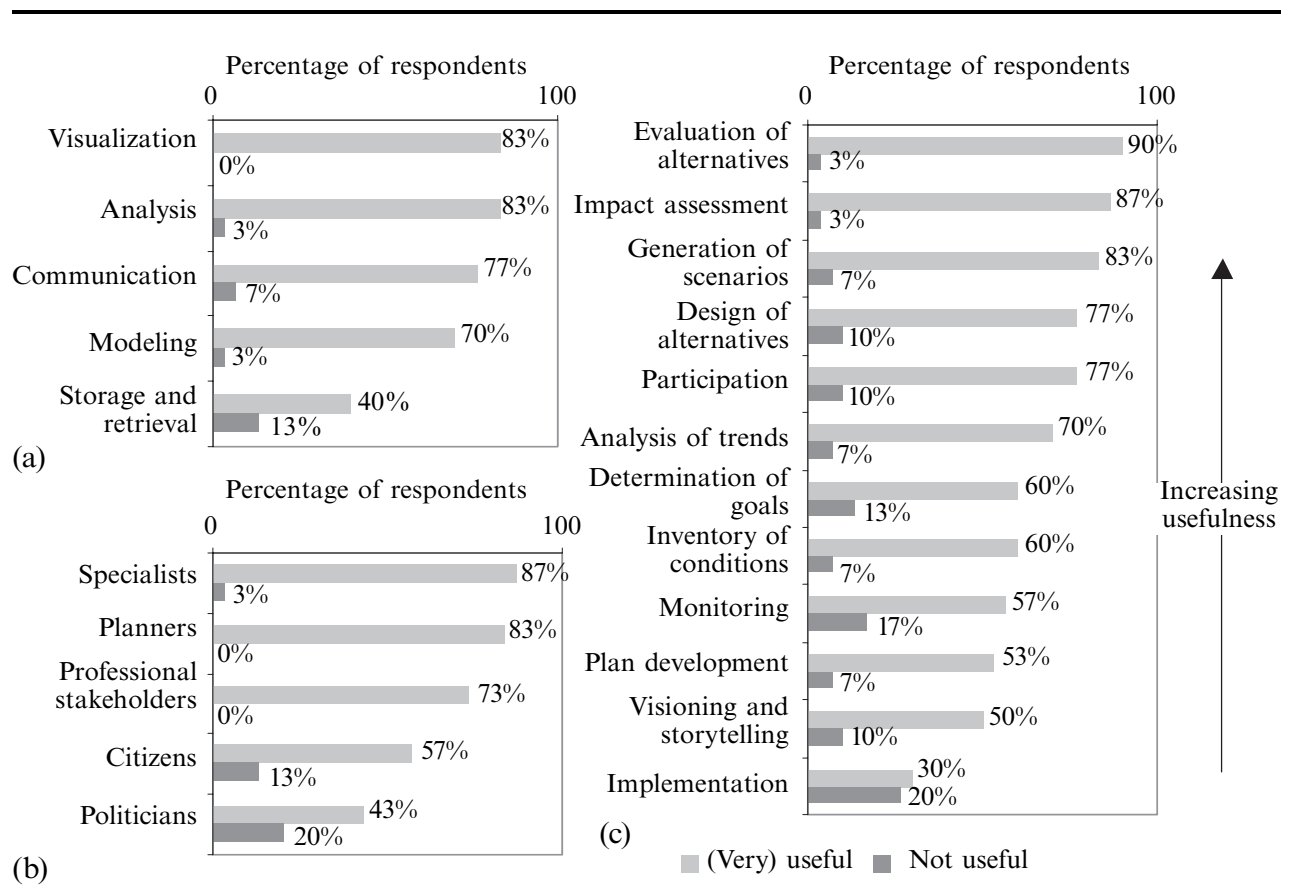

Figure 4. Frequencies of experts indicating level of usefulness of planning-support systems (PSS) for (a) a range of information functions, (b) users, and (c) planning tasks.

Regarding the planning tasks, experts see PSS as most useful for evaluation of alternatives, impact assessment, and generation of scenarios. Analysis shows that these are also the applications with which they have had most experience. Implementation has the highest frequency score on 'not useful'. Analysis shows that respondents have also had the least experience with PSS for implementation. Regarding the PSS information functions, results show that visualization, analysis, communication interface, and modeling are all seen as highly useful functions. Systems that combine these functions would possibly be very useful. Analysis shows that the judgment of analysis and modeling systems, as well as visualization systems, is mostly based upon experience. The function of information storage and retrieval is seen as the least useful in a PSS, having the highest score on 'not useful'. This is probably because this function is seen as simple and obvious in computer-based systems. Analysis shows that experts have less experience with communication instruments.

Regarding the users of PSS, the survey results show that experts see PSS as useful for geo-information specialists, professional planners, and professional stakeholders, these being the highest scoring users. Analysis shows that most experience has been obtained with applications for specialists, citizens, and professional planners. PSS are seen as least useful for politicians (highest score on 'not useful'), who also had the least amount of experience in using PSS. Despite the fact that experts reported a lot of experiences in which citizens used PSS, some of them see PSS as not useful for citizens.

\section{Interpretation}

\subsection{Task - technology - user fit for PSS}

Comparison of the strongest with the most promising combinations of planning task-PSS information function and user-indicates that implementation of PSS is still in a development stage. These strongest combinations in current planning practice 


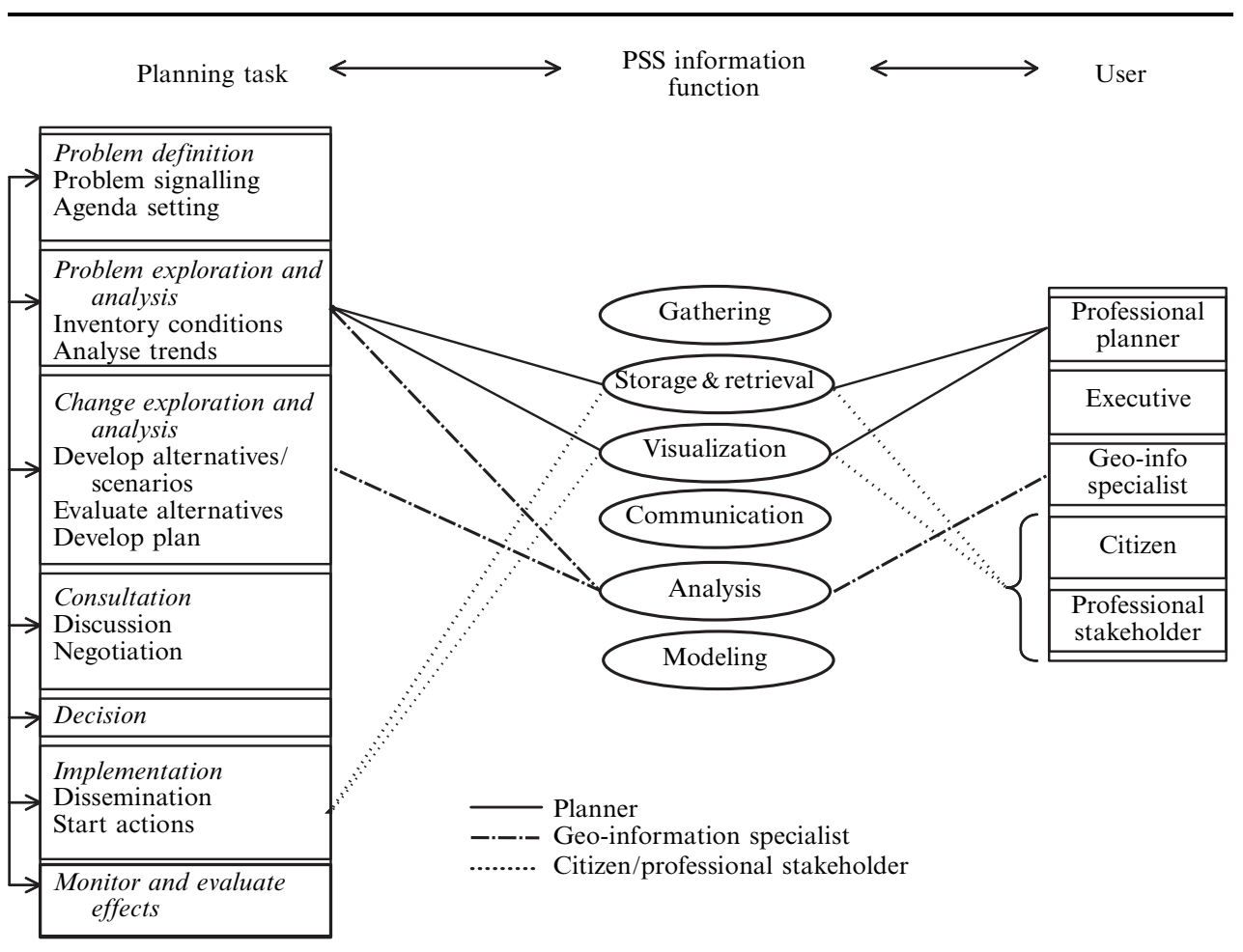

Figure 5. The current strongest combination of planning task-planning-support systems (PSS) information function - user.

and most promising combinations for future planing practice are shown in figures 5 and 6 , and are interpreted in terms of SWOT below.

\subsection{Strengths, weaknesses, opportunities, and threats}

\subsubsection{Strengths}

Figure 5 and the additional results indicate three main strengths of PSS technology in current planning practice. A first strength is that most professional planners experience PSS as useful for information storage and retrieval, as well as simple information visualization, in their current planning activities. Most planners have had experience with systems for such purposes. They often use a centralized database with intranetbased data viewers with simple overlay and zooming functions, predominantly to make inventories of conditions and to help them analyze trends. In particular, the quick and easy visualization functions are seen as highly useful. They judge these nonanalytical instruments as more useful than analysis and modeling instruments. Professional planners indicate that they have little or no experience with advanced analysis and modeling systems.

A second strength is usage for analytical tasks by geo-information specialists. Most geo-information specialist use GIS, to analyze spatial data and produce maps which are used as input by professional planners for problem and change exploration and analysis. In contrast with less skilled users, for geo-information specialists GIS are very much like PSS, as GISs are dedicated to their operating skills. These skills enable them to operate task-undedicated general-purpose tools such as GIS as if they were PSS for the easier tasks. Some geo-information specialists develop tailor-made PSS applications from their generic GIS, to be used by professional planners. In exceptional cases, 


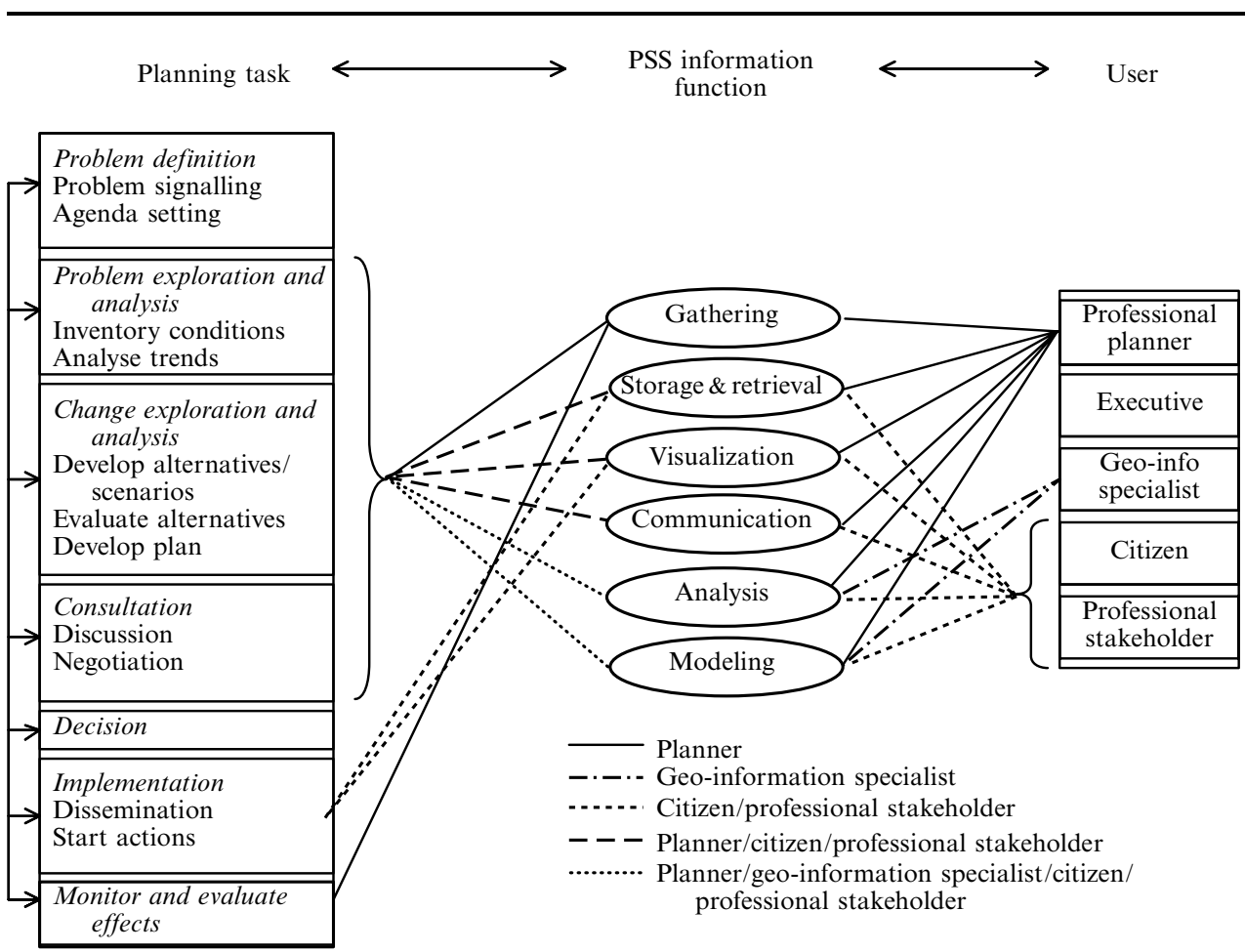

Figure 6. The most promising combinations of planning task-planning-support systems (PSS) information function - user.

geo-information specialists also use modeling for planning support, although they receive less demand for advanced analysis and modeling work.

A third strength is use of PSS by citizens and professional stakeholders in terms of taking notice of planning results disseminated by planning organizations on their websites. The disseminated products are becoming increasingly technically advanced, due to the opportunities offered by geo-information technology and web technology.

\subsubsection{Weaknesses}

Results indicate three main weaknesses of PSS technology in current planning practice. A first weakness is that professional planners' usage of PSS remains limited to rather simple information functions and relatively uncomplex tasks, while system developers focus mostly on advanced instruments for complex change exploration and analysis tasks by planners. In other words, a dichotomy exists between the demands of planning practice and the systems that are being developed. Lack of cooperative development clearly hampers the enhancement of PSS technology, for which we consider the dichotomy to be the greatest weakness of PSS technology. Underlying this weakness is the general weakness of advanced PSS to fit to the nontechnically skilled user in terms of ease of use, and to fit to the planning process and tasks. Many advanced systems try to rationalize things that cannot (yet) be rationalized, and are incapable of handling inherently vague, synergetic, and qualitative elements of planning. Linked to this is the hesitation of professional planners to change their current practices and start using PSS. As long as developers keep focusing primarily on advanced instruments there will remain a gap between their products and the demands of planning practice. As long as users remain hesitant to experiment with advanced PSS, these will not get a chance to mature. The fact that many systems for information 
storage and retrieval that professional planners see as most useful are not even considered PSS by experts is illustrative of the dichotomy.

A second weakness of PSS is their limited use by executives in decision making because most PSS are seen to interfere with the nature of politics as a game of power. Only visualization systems with convincing results and systems that are able to support the power position of the executive are sometimes seen as useful in decision making. Agility with computers and speedy generation of outcomes is vital for such use.

A third weakness is that, although internationally there are large differences, citizens and professional stakeholders currently make little use of PSS. This is a weakness since PSSs could facilitate their participation in planning more widely and to a greater extent. This is caused by, among other things, a low degree of participation of these actors in current planning practice overall and by the sparse usage of PSS in planning processes in general. Consequently, the ability of PSS to support communication between citizens, professional stakeholders, and professional planners remains largely underused.

\subsubsection{Opportunities}

Figure 6 and additional results indicate a range of opportunities for the application of PSS technology in future planning practice in addition to the current applications. A first opportunity is that users see a short-term potential in the use of simple analysisoriented PSS by professional planners for tasks within the problem exploration and analysis stage. In change exploration and analysis, they see some potential for more advanced instruments, but to most this is still far from the current reality. Users indicate that information storage and retrieval systems are most used in planning practice and are the most useful. Therefore we see opportunities for simple systems which rapidly provide highly visual information.

A second opportunity for PSS is that both experts and users see great potential for PSS for advanced visualization of information and communication between professional planners, citizens, and professional stakeholders involved in a process. Visualization is seen as a basis for communication and stimulates creativity during citizen participation and in other interactive settings with planners and stakeholders. In particular, collaborative communication systems, web-based communication systems, and systems that combine information functions for problem and change exploration and analysis and consultation tasks are seen as promising. The opportunities for such applications are likely to increase because of the increasingly participatory nature of planning.

A third opportunity for PSS technology is use in analysis and modeling applications. Both experts and system developers see the core benefit of PSS in these applications. Although researchers and geo-information specialists are at present the main users of analysis and modeling systems, both experts and system developers see significant potential for usage by planners and professional stakeholders if the systems are made user friendly and fit to the planning process. Most experts see such PSS as suitable for the generation of scenarios, the design of alternatives, impact assessment, the evaluation of alternatives, and for the development of a plan. Users are mostly unaware of these opportunities and have mixed feelings about the potential of advanced systems.

\subsubsection{Threats}

The results indicate several threats that may prevent realization of the opportunities for PSS technology. A first threat is that the dichotomy between supply and demand of PSS may not be removed. Therefore, increased cooperation between system developers and practitioners is needed. In this, geo-information specialists within planning organizations can play an important role in communication between the 
supply and demand sides. System developers should focus on the niches identified by experts and users as strengths or opportunities. This will often mean, at least in the first instance, restricting oneself to developing simple low-tech systems instead of immediately going for the most sophisticated technology.

A second threat is that the current bottlenecks blocking development of PSS and their diffusion into planning practice may not be removed. Earlier we found that lack of awareness, lack of experience, and lack of general intention to use PSS among users were the main bottlenecks that hold back diffusion of PSS (Vonk et al, 2005a). A second study showed that power issues hold back PSS diffusion: those in power are afraid to lose their position to instruments they cannot control (Vonk et al, 2005b). Furthermore, these studies suggest that a perceived lack of overview of (short-term) benefits of using PSS holds those in power back from adopting PSS. A third threat is going to practice with PSS in early stages of development. Many such PSS will not be sufficiently dedicated to the demands of planning processes and users. The consequent troublesome application of the system may cause an image of PSS as being difficult to handle to be formed or upheld among users. PSS in early stages of development should therefore first be applied in research simulation settings, rather than real planning processes, in order for lessons for improvement to be learned.

\section{Conclusions and recommendations}

From our study of SWOT, we conclude that the current large diversity of PSS, the lack of standards, and little usage in practice, indicate that PSS technology is still in an early and exploratory stage of growth. PSS are far from being standardized software instruments, widely used in planning practice. The ongoing diversification and lack of standards associated with this phase causes ambiguity regarding what constitutes PSS, and makes it virtually impossible to arrive at a suitable instrumental description of current PSS. In addition, the continuously improving technology forces instruments that were previously seen as PSS to make room for new instruments that better support planning. This also causes the practical meaning of PSS to shift in time. Nonetheless, results indicate that most experiences with PSS application are evaluated positively, across a broad range of application types.

We furthermore conclude that in the current state of PSS the lack of insights in mutual demands, knowledge, and possibilities between users and system developers causes a dichotomy to persist between developed systems and user demands. System developers develop cutting-edge analysis and spatial modeling systems. Although users are quite positive about the potential of many such systems, their demand is for much simpler systems, dedicated to the storage, retrieval, visualization, and communication of information during problem analysis and exploration. Bridging the gap between researchers' activities and the practical needs of practitioners presents a real obstacle to PSS development and adoption.

To decrease the dichotomy between users and system developers, we recommend that PSS users increase internal and external cooperation on information-technology development and start experimenting with PSS instruments that go further than simple data viewers. Although the slightly more advanced systems may not yet be perfect, continued development in practice is extremely useful for systems that have reached a certain stage of laboratory development (Oudshoorn and Pinch, 2003). Likewise, it is recommended that PSS developers should increase contact with users in order to develop products fit for practice. They should realize that there is significant research potential in the dedication of systems to planning and planners. We recommend they develop their instruments within the niches that professional planners see as the most promising, and go step by step in further development to make sure that the developed 
systems appeal to planners instead of to only researchers. Exploration of new niches could perhaps be better done in development laboratories.

To enable successful cooperation, the various user groups, system developers, and researchers must realize that they are all part of the innovation network concerning PSS. The development of good PSS is expected to benefit from the investment of time and effort by all actors in this network (Novikova, 2005; Pittaway et al, 2004). We recommend they engage in a form of interactive learning to develop PSS technology (Christensen and Lundvall, 2004, page 187). The organizational form we recommend for such efforts is the so-called 'communities of practice' (Brown and Duguid, 1991). These groups of people who share a concern or a passion for something they do and learn how to do it better as they interact regularly (Wenger, 1998). The involvement of all the relevant actors of the innovation network concerning PSS in such communities may enable them to find common ground for experimenting with and testing instruments in practice without being blocked halfway by factors that were unaccounted for. We expect that the sharing of knowledge between different communities will stimulate the development of PSS in general, and will make them more attuned and dedicated to specific practices in particular (Brown and Duguid, 1991). A community of practice with planning practitioners, researchers, and system developers, initiated in 1998 by the US Department of Energy, has already generated some highly useful insights into requirements for attuned and dedicated systems (Snyder, 2003). To researchers, we suggest taking an active role in these communities. On the conceptual level, they can contribute to the communities by providing guidelines for cooperation and by providing the latest research results. On the content level, the communities will facilitate them to study the application of PSS dedicated to certain planning tasks in practice in order to learn lessons and set up standards of best practice. A basic prerequisite for the proper functioning of these communities, however, is a common concern or passion. In the case of PSS, this common concern or passion could be the need to tackle the ever-increasing complexity of planning tasks.

Acknowledgements. The authors kindly thank all respondents to our web survey and the employees of the twelve Dutch provinces who were interviewed on their participation. We also offer special thanks to Richard Klosterman and Richard Kingston for letting us use their listservs, and Edwin Bleijinga for his contribution to the interviews. Finally, we thank the anonymous referees for their comments.

\section{References}

Alexander E R, 1998, "Doing the 'impossible': notes for a general theory of planning" Environment and Planning B: Planning and Design $25667-680$

Archibugi F, 2004, "Planning theory: reconstruction or requiem for planning" European Planning Studies $12425-445$

Batty M, 1995, "Planning support systems and the new logic of computation" Regional Development Dialogue $161-17$

Beaudry A, Pinsonneault A, 2005, “Understanding user responses to information technology: a coping model of user adaptation" MIS Quarterly 29493 - 524

Bishop I, 1998, "Planning support: hardware and software in search of a system" Computers Environment and Urban Systems $22189-202$

Brail R, Klosterman R (Eds), 2001 Planning Support Systems, Integrating Geographic Information Systems, Models and Visualization Tools (ESRI Press, Redlands, CA)

Brown J, Duguid P, 1991, "Organizational learning and communities of practice: toward a unified view of working, learning, and innovation" Organization Science 2 40-57

Burrough P, McDonnel R, 1998 Principles of Geographical Information Systems (Oxford University Press, Oxford)

Christensen J, Lundvall B, 2004 Product Innovation, Interactive Learning and Economic Performance (Elsevier, Amsterdam) 
Couclelis H, 2003, "Where has the future gone? Rethinking the role of integrated land use models in spatial planning", in Framing Land Use Dynamics: Reviewed Abstracts International Conference 16-18 April, 2003 Faculty of Geographical Sciences, Utrecht University, Utrecht, pp $27-28$

Craig W, Harris T, Weiner D (Eds), 2002 Community Participation and Geographic Information Systems (Taylor and Francis, London)

Davis F, 1989, "Perceived usefulness, perceived ease-of-use, and user acceptance of information technology" MIS Quarterly 13319 - 339

Dishaw M, Strong D, 1999, "Extending the technology acceptance model with task - technology fit constructs" Information and Management 36 9-21

Dishaw M, Strong D, Bandy B, 2002, "Extending the task - technology fit model with self-efficacy constructs", in Eighth Americas Conference on Information Systems, AMCIS 2002 Association for Information Systems, Dallas, pp 1021 - 1027

Driessen P P J, Glasbergen P, Verdaas C, 2001, "Interactive policy-making - a model of management for public works" European Journal of Operational Research 128322 - 337

Geertman S, 1996 Physical Planning and Geographical Information: A Reconnaissance of Geo-IT Methodology $\mathrm{PhD}$ thesis, Utrecht University, Utrecht

Geertman S, Stillwell J (Eds), 2003a Planning Support Systems in Practice 1st edition (Springer, Berlin)

Geertman S, Stillwell J, 2003b, "Planning support systems: an introduction", in Planning Support Systems in Practice Eds S Geertman, J Stillwell (Springer, Berlin) pp 3-23

Geertman S, Stillwell J, 2004, "Planning support systems: an inventory of current practice" Computers Environment and Urban Systems 28291 - 310

Goodhue D L, Thompson R L, 1995, "Task - technology fit and individual performance” MIS Quarterly $19213-235$

Hall P, 2002, "Planning: millenial retrospect and prospect" Progress in Planning 57263 - 284

Harris B, 1960, "Plan or projection: an examination of the use of models in planning" Journal of the American Institute of Planners 26(4) $265-272$

Jankowski P, Nyerges T, 2001 Geographic Information systems for Group Decision Making (Taylor and Francis, London)

Klosterman R, 1997, "Planning support systems: a new perspective on computer-aided planning" Journal of Planning Education and Research $1745-54$

Klosterman R, Pettit C, 2005, "An update on planning support systems" Environment and Planning B: Planning and Design $32477-484$

Laninga T, 2001, "Conference proceedings of Tools for Community Design and Decision Making IV”, http://www.placematters.us/Documents/EVENTS/TCDDMConference/DenverTCDDM4.html

Lundvall B, 1988, "Innovation as an interactive process: from user-producer interaction to the national system of innovation", in Technical Change and Economic Theory Eds G Dosi, C Freeman, R Nelson, G Silverberg, L Soete (Pinter, London) pp 349-369

Mandelbaum S J, 1979, "A complete general theory of planning is impossible" Policy Sciences $1159-71$

Margerum R, 2002, "Evaluating collaborative planning, implications from an empirical analysis of growth management" Journal of the American Planning Association 68 179-193

Novikova J, 2005, "Firms of networks: in search of the locus of innovation", in Proceedings of DRUID Academy's 2005 Winter Conference on Industrial Evolution and Dynamics Aalborg, Denmark, http://www.druid.dk/ocs/viewpaper/327.pdf

Oudshoorn N, Pinch T, 2003, "How users and non-users matter", in How Users Matter, The Co-construction of Users and Technology Eds N Oudshoorn, T Pinch (MIT Press, Cambridge, MA) pp 4-22

Pittaway L, Robertson M, Minur K, Denyer D, 2004, "Networking and innovation: a systematic review of the evidence", WP 2004/016, Lancaster University Management School, Lancaster

Rogers E, 2003 Diffusion of Innovations 5th edition (Free Press, New York)

Snyder K, 2003, "Tools for community design and decision-making", in Planning Support Systems in Practice Eds S Geertman, J Stillwell (Springer, Berlin) pp 99-120

Stillwell J, Geertman S, Openshaw S, 1999a, "Developments in geographical information and planning", in Geographical Information and Planning Eds J Stillwell, S Geertman, S Openshaw (Springer, Berlin) pp 3-22

Stillwell J C H, Geertman S, Openshaw S, 1999b Geographical Information and Planning (Springer, Berlin) 
Venkatesh V, Morris M, Davis G, Davis F, 2004, “User acceptance of information technology: toward a unified view" MIS Quarterly $27425-478$

Vonk G, Geertman S, Schot P, 2005a, "Bottlenecks blocking widespread usage of planning support systems" Environment and Planning A 37 909-924

Vonk G, Geertman S, Schot P, 2005b, "New technologies stuck in old hierarchies: an analysis of the diffusion of geo-information technologies in Dutch planning organizations" Public Administration Review forthcoming

Wenger E, 1998, Communities of Practice: Learning, Meaning, and Identity (Cambridge University Press, Cambridge) 
Conditions of use. This article may be downloaded from the E\&P website for personal research by members of subscribing organisations. This PDF may not be placed on any website (or other online distribution system) without permission of the publisher. 